\title{
$M^{\text {me }}$ CORALIE CAHEN
}

On lisait dans Le Temps, le 10 mars dernier :

« Après une très longue et très douloureuse maladie, $\mathrm{M}^{\text {me }}$ Coralie Cahen vient de s'éteindre, nous laissant le souvenir d'une vie admirable. Née à Nancy en 1832, Mile Coralie Lévy avait épousé M. Cahen, médecin en chef de la Compagnie du Nord. Peu de temps avant la guerre de 1870 , elle perdait sa fille unique et son mari.. Il y avait en elle un instinct profond de dévouement. Ne pouvant plus se dévouer à sa famille, elle se dévoua à sa patrie.

« Dès l'ouverture des hostilités, elle s'installait à Metz en qualité de vice-présidente de la Société de secours aux blessés. Là elle eut l'idée généreuse d'organiser, près de la préfecture, une ambulance uniquement destinée aux sous-officiers et aux simples soldats. Elle prévoyait avec raison que les officiers seraient recueillis chez les habitants et y recevraient les meilleurs soins. Elle se réservait pour ceux qui avaient moins de chances d'être bien soignés.

«Aux premiers coups de canon, $\mathrm{M}^{\mathrm{me}}$ Cahen était prête et relevait les premiers blessés sur le champ de bataille de Borny. Pendant tout le siège elle resta à son poste, sauvant chaque jour un certain nombre de vies humaines. Après la capitulation, elle gagna Tours par la Suisse et se mit à la disposition du gouvernement de la Défense nationale.

«En prévision de la lutte qui allait s'ouvrir sur les bords de la Loire, Gambetta confia à $\mathrm{M}^{\mathrm{m}}$ Cahen la mission de transformer en hòpital les bâtiments du lycéede Vendôme. Plusieurs médecins et sept religieuses lui furent adjoints. C'est là que, pendant plus de trois mois, la vaillante femme a recueilli et soigné des milliers de blessés appartenant aux deux armées. Quand les Prussiens occupèrent Vendôme, ils voulurent remplacer le drapeau français qui flottait sur l'hòpital par le drapeau allemand. Mme Cahen s'y opposa énergiquement, en invoquant le témoignage des blessés allemands qu'elle avait secourus avec autant de dévouement que les blessés français. Les vainqueurs ne se contentèrent pas de lui donner satisfaction, ils reconnurent avec bonne grâce qu'elle les avait forcés à s'incliner devant sa charité et devant son patriotisme. «Après être restée six mois sur la brèche, tant à Metz qu'à 


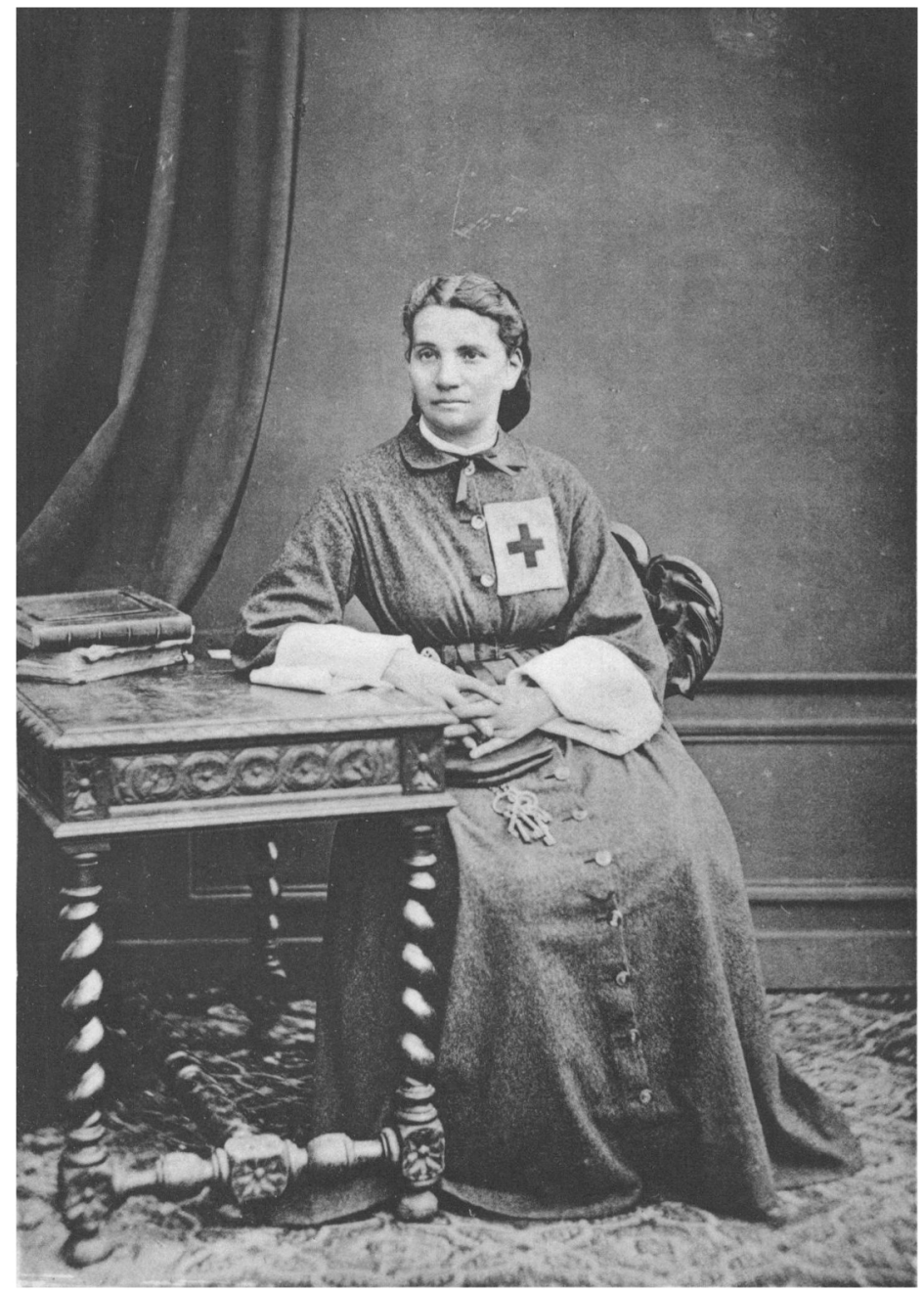

\section{MADAME CORALIE CAHEN}

Ancienne vice-présidente de la Croix-Rouge française DÉCÉDÉE LE IO MARS I 899 
Vendòme, $M^{\text {me }}$ Cahen avait droit au repos. Mais elle était de ces natures ardentes qui ne se reposent jamais tant qu'il reste quelque chose à faire. Rentrée en Lorraine, elle voyait passer à Lunéville et à Nancy les prisonniers français qui revenait de captivité. En causant avec eux, elle découvrit qu'un certain nombre de leurs camarades devaient encore être retenus en Allemagne pour des fautes contre la discipline ou pour des délits de droit commun.

“Aussitòt elle arrêta son plan. Elle irait elle-même dans les forteresses allemandes, à la recherche des prisonniers français, et ne rentrerait définitivement en France qu'après avoir obtenu la liberté de tous. D'autres négociateurs auraient échoué dans une si difficile entreprise, mais elle arrivait en Allemagne précédée d'une grande réputation. Tout le monde y savait avec quel dévouement elle avait soigné à Vendòme les blessés allemands. L'impératrice Augusta, si pitoyable pour les Français, la reçut à bras ouverts et lui facilita sa tâche. A la fin de l'année 1872, Mme Cahen avait visité 66 forteresses et il ne restail plus, en Allemagne un seul prisonnier français.

« Elle obtenait un autre résultat non moins important. Beaucoup de nos soldats avaient disparu, sans que le gouvernement allemand donnât sur eux aucun renseignement. Leurs familles attendaient avec anxiété de leurs nouvelles. Le Ministère de la guerre et celui des affaires étrangères étaient assaillis de questions auxquelles ils ne pouvaient répondre. $\mathrm{M}^{\mathrm{me}}$ Gahen sut découvrir à Berlin le bureau où se trouvaient concentrés tous les renseignements nécessaires et rapporta à Paris 59,000 fiches individuelles, fixant la situation de tous les disparus, morts ou encore en traitement dans les hôpitaux allemands.

( Elle avait obtenu la croix pour plusieurs de ses collaborateurs, elle n'avait rien demandé, rien voulu pour elle-même. Ce fut M. de Freycinet qui, en 1889, trouvant au Ministère les magnifiques états de service qu'un article du Temps lui avait signalés, voulut la décorer au titre militaire et lui dit gracieusement : «Madame, je a remercie mes prédécesseurs qui m'ont laissé le plaisir et l'honneur c de vous accorder une récompense si bien et depuis si long(temps méritée.)

( Depuis la guerre, $\mathrm{M}^{\mathrm{me}}$ Cahen concentrait son activité sur l'orphelinat israélite de Neuilly, fondé par elle, et sur l'Association des Dames françaises, dont elle était une des vice-présidentes. Elle 
meurt entourée d'illustres amitiés, honorée et admirée de tous ceux qui l'ont connue. Au milieu des plus cruelles souffrances, elle a voulu dire adieu à chacun de ses amis, leur donnant ainsi l'exemple d'une belle mort, comme elle leur avait donné l'exemple d'une belle vie.

(A. MÉzières. 》

Nous avons tenu à reproduire intégralement la notice qu'on vient de lire, parce qu'elle donne une idée très juste et complète de la belle carrière de $\mathbf{M}^{\mathrm{m} e}$ Cahen, cette héroïne de la charité, sur la tombe de laquelle nous tenons à apporter aussi notre tribut de regrets. Nous nous serions fait un devoir de retracer nous-mêmes ses travaux, si un éminent académicien ne s'était acquitté avant nous de cette pieuse tâche.

Nous éprouvions en effet la plus vive sympathie et la plus grande estime pour la défunte, depuis la visite inoubliable qu'elle daigna nous faire à Genève, alors que, toute pénétrée encore des émotions douloureuses du siège de Metz, elle traversait notre ville pour regagner la France et y commencer une nouvelle série d'actes de dévouement rappelés par son biographe. Demeurés en relations avec elle, nous avons toujours suivi dès lors, avec un affectueux et profond intérêt, les diverses phases de son activité, el sa mort nous a causé une vraie tristesse.

Le jour de ses obsèques, les honneurs militaires lui furent rendus par un détachement d'infanterie.

Nous nous permettons de joindre à ces lignes une reproduction de la photographie ${ }^{1}$ que $\mathbf{M}^{\text {me }}$ Cahen nous avait laissée en 1870 , comme souvenir de sa trop courte apparition parmi nous, avec le costume d'infirmière qu'elle portait alors.

\section{GRANDE-BRETAGNE}

\section{LA SOCIÉTÉ ANGLAISE EN 1897 ET 1898}

Le dernier rapport anglais avait paru en décembre 1896 à la fin de la rébellion dans la Rhodesia. Celui qui vient d'être publié rend

1 Voir la planche ci-jointe. 